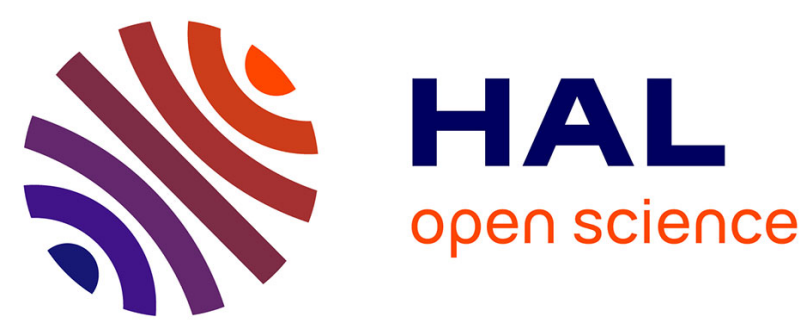

\title{
The effect of the sodium content on the structure and the optical properties of thermally poled sodium and niobium borophosphate glasses
}

Lara Karam, Frédéric Adamietz, Vincent Rodriguez, Flavie Bondu, Antoine Lepicard, Thierry Cardinal, Evelyne Fargin, Kathleen Richardson, Marc Dussauze

\section{To cite this version:}

Lara Karam, Frédéric Adamietz, Vincent Rodriguez, Flavie Bondu, Antoine Lepicard, et al.. The effect of the sodium content on the structure and the optical properties of thermally poled sodium and niobium borophosphate glasses. Journal of Applied Physics, 2020, 128 (4), 043106 (11 p.). 10.1063/5.0013383 . hal-02972758

\section{HAL Id: hal-02972758 https://hal.science/hal-02972758}

Submitted on 20 Oct 2020

HAL is a multi-disciplinary open access archive for the deposit and dissemination of scientific research documents, whether they are published or not. The documents may come from teaching and research institutions in France or abroad, or from public or private research centers.
L'archive ouverte pluridisciplinaire HAL, est destinée au dépôt et à la diffusion de documents scientifiques de niveau recherche, publiés ou non, émanant des établissements d'enseignement et de recherche français ou étrangers, des laboratoires publics ou privés. 


\title{
The effect of the sodium content on the structure and the optical properties of thermally poled sodium and niobium borophosphate glasses
}

Lara Karam, ${ }^{7}$ Frédéric Adamietz, ${ }^{7}$ Vincent Rodriguez, ${ }^{7}$ Flavie Bondu, ${ }^{7}$ Antoine Lepicard, ${ }^{1}$ Thierry Cardinal, ${ }^{2}$ Evelyne Fargin, ${ }^{2}$ Kathleen Richardson, ${ }^{3}$ and Marc Dussauze ${ }^{1, a)}$

\author{
AFFILIATIONS \\ ${ }^{1}$ Institut des Sciences Moléculaires, UMR 5255, Université de Bordeaux, 351 cours de la Libération, 33405 Talence Cedex, France \\ ${ }^{2}$ Institut de Chimie de la Matière Condensée de Bordeaux, Université de Bordeaux, 87 Avenue du Dr Schweitzer, F-33608 Pessac, \\ France \\ ${ }^{3}$ CREOL, College of Optics and Photonics and Department of Materials Science and Engineering, University of Central Florida, \\ Orlando, Florida 32816, USA
}

a) Author to whom correspondence should be addressed: marc.dussauze@u-bordeaux.fr

\begin{abstract}
Six niobium rich glasses presenting different sodium contents were synthetized. On the basis of complementary infrared and Raman analysis, the influence of the sodium content and its role on the structure of the glasses prior to and following poling was examined. Correlative second harmonic generation (SHG)/Raman microscopy on the poled glasses cross section has shown a co-localization of the SHG signal and the structural variations. It also evidenced similar structural rearrangements whether sodium is removed through poling $\left(230-300^{\circ} \mathrm{C}\right)$ or through the alkali content defined by the starting glass compositions (melted at $1300-1500^{\circ} \mathrm{C}$ ). The effect of the sodium content on the optical properties, prior to and after thermal poling, is also discussed. It was found that refractive index variations induced by poling (ranging between $10^{-3}$ and $3 \times 10^{-2}$ ) are mainly the result of a density decrease in the poled region rather than compositional and structural changes. The electro-optic origin of the poling-induced second order nonlinear response is confirmed by the Maker Fringe SHG analysis, and the evolution of $\chi^{(2)}(2-2.5 \mathrm{pm} / \mathrm{V})$ with the sodium content is discussed based on a selection of parameters influencing either the third order susceptibility $\left[\chi^{(3)}\right]$ or the internal electric field strength of the poled layer.
\end{abstract}

\section{INTRODUCTION}

The development of technologies such as photonic integrated circuits (PICs) requires the use of a combination of materials presenting and/or mixing different functionalities. Such optical functionality can include emission as light sources, guiding elements, diffractive elements, and materials with a desired nonlinear response. These attributes can also be combined with electrical or chemical functionalities as seen in sensing applications. Glasses are interesting materials in this domain thanks to the versatility of their composition and optical properties, their simple and low cost fabrication process when compared to their crystalline counterparts, and their isotropic nature that reduces device geometry restrictions.
Thermal poling involves the application of a DC field to a heated glass sample providing sufficient mobility to ionic charge carriers, and then cooling the sample back to room temperature before switching the voltage off. This process enables control of several properties of the glass. The reactivity of the glass can be modified by poling; ${ }^{1-3}$ as an example, authors took advantage of this process to design diffraction gratings thanks to the selective etching response imparted by the poling process. ${ }^{4,5}$ The process is accompanied by a modification of the linear optical properties ${ }^{6}$ making possible the fabrication of micro-optics elements such as arrays of micro-lenses ${ }^{7}$ or waveguides. ${ }^{8}$ It has to be noted that among the different phenomena described after poling, a majority of studies are dedicated to second order nonlinear (SONL) 
properties. $^{9-18}$ Many active optical devices such as electro-optical switches or interferometers rely on SONL properties. Due to their isotropic nature, glasses cannot be considered for such applications as their SONL response is zero. Upon thermal poling, however, the centrosymmetry of the glass is broken and a space charge is implemented at its surface. This leads to an induced second order optical susceptibility $\left[\chi^{(2)}\right]$ that allows one to consider glasses for active optical devices. Poling-induced $\chi^{(2)}$ was first observed in fused silica ${ }^{9}$ but with a low magnitude ${ }^{10,11}(<0.3 \mathrm{pm} / \mathrm{V})$. Since then, studies have been extended to many different glass families including silicate, ${ }^{19-21}$ heavy metal oxides, ${ }^{12-14}$ and chalcogenides. ${ }^{7,15,16}$ Induced second order susceptibilities as high as $5 \mathrm{pm} / \mathrm{V}$ have been obtained in sodium and niobium borophosphate glasses ${ }^{17,18}$ and, recently, even up to $29 \mathrm{pm} / \mathrm{V}$ for micro-polarized amorphous sodo niobate thin films prepared by sputtering. ${ }^{22}$ This value is one order of magnitude higher than that of fused silica and much more suitable for potential applications as it approaches levels comparable to some crystalline candidate materials.

Sodium and borophosphate glass systems have been studied for a long time and are well known. ${ }^{6,14,17,18,23,24}$ Previous works on these glasses have shown that upon poling, sodium is depleted on the order of several micrometers, within a layer under the anode. ${ }^{17}$ From these studies, one can wonder if sodium, as the mobile cation, could provide a lever enabling modification of the glass' post-poled optical properties. In this paper, a fundamental study of the influence of the sodium content is realized through the synthesis of new glass compositions with different sodium doping levels. The relationship between the glass chemistry, the glass structure, and the properties before and after poling is presented.

\section{EXPERIMENTAL SECTION}

\section{A. Glass synthesis}

A series of five niobium borophosphate (bpn) and sodium glasses was synthetized by melt-quenching. The bulk glasses are referred to as bpn-XNa with $\mathrm{X}$ being the nominal atomic percentage of sodium. $\mathrm{X}$ ranges from 3 to 12 at. \%. bpn-10Na of nominal composition $0.58\left(0.95 \mathrm{NaPO}_{3}+0.05 \mathrm{Na}_{2} \mathrm{~B}_{4} \mathrm{O}_{7}\right)+0.42 \mathrm{Nb}_{2} \mathrm{O}_{5}$ was synthetized following the procedure described in a previous work. ${ }^{17}$ High purity $\mathrm{NaPO}_{3}, \mathrm{Na}_{2} \mathrm{~B}_{4} \mathrm{O}_{7}$, and $\mathrm{Nb}_{2} \mathrm{O}_{5}$ powders were mixed, melted at $1300^{\circ} \mathrm{C}$ in an open platinum crucible, and quenched in a brass preform. The resulting glass was annealed overnight in air at $15^{\circ} \mathrm{C}$ under the glass transition temperature $\left(\mathrm{T}_{\mathrm{g}}\right)$. In order to modify the sodium content but not the other components' ratio, other precursors were chosen as sources of glass components, including $\mathrm{H}_{3} \mathrm{PO}_{3}, \mathrm{H}_{3} \mathrm{BO}_{3}, \mathrm{Nb}_{2} \mathrm{O}_{5}, \mathrm{NaPO}_{3}$, and $\mathrm{Na}_{2} \mathrm{CO}_{3}$. The nominal compositions of the resulting glasses can written as $(1-\mathrm{x})[0.58[0.95[(1-\mathrm{y})$ $\left.\left.\left.\mathrm{NaPO}_{3}+\mathrm{y} / 2 \mathrm{P}_{2} \mathrm{O}_{5}\right]+0.05\left(2 \mathrm{~B}_{2} \mathrm{O}_{3}\right)\right]+0.42 \mathrm{Nb}_{2} \mathrm{O}_{5}\right]+\mathrm{xNa}_{2} \mathrm{O}$, and the corresponding nominal atomic compositions are reported in Table I for clarity. In the modified glasses, reagent powders were mixed, ground, and poured in a Teflon beaker to which $\mathrm{H}_{3} \mathrm{PO}_{3}$ (liquid) was added. The beaker was left in a sand bath at $80^{\circ} \mathrm{C}$ overnight to initiate the reaction. The resulting powder was mixed, poured into an open platinum crucible, heated at $800^{\circ} \mathrm{C}$ for $3 \mathrm{~h}$ to evaporate the carbonated species, and melted between $1300^{\circ} \mathrm{C}$ and $1500{ }^{\circ} \mathrm{C}$ depending on the composition. The melt was then quenched in a brass preform and annealed at a $\mathrm{T}_{\mathrm{g}}$ of $-15^{\circ} \mathrm{C}$. The glasses were then cut and optically polished on both sides to obtain $1 \mathrm{~mm}$ thick samples. Energy dispersive spectroscopy (EDS) measurements were carried out on a Cameca SX100 to determine the real composition of the samples.

The glass transition temperatures were determined by differential scanning calorimetry (DSC) with a precision of $\pm 2{ }^{\circ} \mathrm{C}$ on a Netzsch DSC Pegasus 404PC apparatus using Pt pans at a heating rate of $10^{\circ} \mathrm{C} / \mathrm{min}$. Glass densities were determined using the Archimedes method by immersing the samples in diethyl phtalate at room temperatures. Measurements were performed on different samples from different syntheses to determine the error bar.

\section{B. Thermal poling}

Thermal poling was performed under flowing nitrogen. Glass samples of $1 \times 1 \mathrm{~cm}^{2}$ size and $1 \mathrm{~mm}$ thick and were heated at a rate of $15^{\circ} \mathrm{C} / \mathrm{min}$ to the target temperature (detailed in Sec. III A). A DC voltage of $800 \mathrm{~V}$ was then applied (with a $320 \mathrm{~V} / \mathrm{min}$ rate) and left on for $30 \mathrm{~min}$. The sample was then brought back to ambient temperature before removal of the DC field. The anode (purchased from the LAAS-CNRS facilities in Toulouse) consisted of a $200 \mathrm{~nm}$ film of platinum deposited on a soda-lime silicate glass slide $\left(5 \times 5 \times 1 \mathrm{~mm}^{3}\right)$. On the cathode side, a piece of silicon wafer was used, and a microscope coverslip was placed between the silicon and the sample to preserve the optical quality of the sample on this side.

TABLE I. Theoretical and measured elemental composition (at. \%) of the bulk glasses (bpn-12Na was not measured), as quantified by energy dispersive x-ray spectrometry or EDS.

\begin{tabular}{|c|c|c|c|c|c|c|c|c|c|c|c|c|}
\hline & \multicolumn{6}{|c|}{ Theoretical composition (at. \%) } & \multicolumn{6}{|c|}{ Measured composition (at. \%) (EDS) } \\
\hline & $\mathrm{B}$ & $\mathrm{P}$ & $\mathrm{Nb}$ & $\mathrm{Na}$ & $\mathrm{O}$ & $\mathrm{Nb} / \mathrm{P}$ & B & $\mathrm{P}$ & $\mathrm{Nb}$ & $\mathrm{Na}$ & $\mathrm{O}^{\mathrm{a}}$ & $\mathrm{Nb} / \mathrm{P}$ \\
\hline bpn $-12 \mathrm{Na}$ & 1.8 & 8.5 & 13.0 & 12.0 & 64.7 & 1.53 & $\ldots$ & $\ldots$ & $\ldots$ & $\ldots$ & $\ldots$ & $\ldots$ \\
\hline bpn $-10 \mathrm{Na}$ & 1.9 & 9.1 & 13.8 & 10.0 & 65.1 & 1.53 & 1.0 & 8.8 & 14.3 & 11.0 & 64.8 & 1.62 \\
\hline bpn-9Na & 1.9 & 9.3 & 14.1 & 9.0 & 65.6 & 1.53 & 1.8 & 8.7 & 14.4 & 9.8 & 65.3 & 1.65 \\
\hline bpn-7Na & 2.1 & 10.0 & 15.2 & 7.0 & 65.8 & 1.53 & 3.0 & 8.7 & 14.5 & 7.3 & 66.4 & 1.67 \\
\hline bpn- $-5 \mathrm{Na}$ & 2.2 & 10.6 & 16.2 & 5.0 & 65.9 & 1.53 & 2.7 & 9.5 & 15.1 & 5.1 & 67.6 & 1.59 \\
\hline $\mathrm{bpn}-3 \mathrm{Na}$ & 2.4 & 11.3 & 17.2 & 3.0 & 66.1 & 1.52 & 2.6 & 9.5 & 16.0 & 3.0 & 68.9 & 1.68 \\
\hline
\end{tabular}

${ }^{\mathrm{a}}$ The content of oxygen $(\mathrm{O})$ was not measured but adjusted to correspond with the stoichiometry. 
After poling, the elemental concentration profile under the anode was determined by secondary ion mass spectroscopy (SIMS) measurements that were performed on a PHI Adept 1010 dynamic SIMS system.

\section{IR spectroscopy and coupled Raman-SHG microscopy}

Correlative micro-Raman and micro-SHG measurements were recorded in the backscattering mode on a modified micro-Raman spectrometer HR800 (Horiba/Jobin Yvon). ${ }^{25}$ A CW laser operating at $532 \mathrm{~nm}$ was used for the Raman and a picosecond pulsed laser at $1064 \mathrm{~nm}$ (EKSPLA PL2200: pulse duration 65 ps and repetition rate $2 \mathrm{kHz}$ ) was used for the micro-SHG measurements with typical maximum average power $\sim 1 \mathrm{~mW}$. The typical resolution of the Raman is $2.5 \mathrm{~cm}^{-1}$. A Mitutuyo $20 \times$ objective was used on the samples prior to poling. A Mitutuyo $100 \times$ long working distance objective (numerical aperture of 0.5 ) was used to carry out the measurements on the cross section of the poled samples.

Reflectance spectra were recorded in primary vacuum on a Fourier Vertex $70 \mathrm{~V}$ spectrometer equipped with a Globar type source, a deuterated triglycine sulfate detector, and a mid/far infrared range beam splitter. The spectra recorded between 100 and $7000 \mathrm{~cm}^{-1}$ (resolution of $4 \mathrm{~cm}^{-1}$ ) resulted of a total average of 200 scans. From these spectra, the absorbance spectra were calculated by the Kramers-Krönig analysis. ${ }^{26}$

\section{Optical properties}

Linear refractive indices were measured on the bulk samples using the Brewster's angle method at different wavelengths (532, 639,935 , and $1550 \mathrm{~nm}$ ). The dispersion curves were obtained by fitting the experimental data with a Cauchy fit. ${ }^{27}$

To characterize the refractive index change induced by poling, we used the method described in Ref. 6 based on optical simulations of the interference fringes measured by IR reflectance microscopy. Here, the spectra were recorded on both pristine bulk and post-poled sample surfaces in reflection (at normal incidence) on a FTIR spectrometer (Nicolet) equipped with an IR microscope (Nic-Plan). The spectra correspond to the average of 200 scans with a resolution of $2 \mathrm{~cm}^{-1}$.

The second order optical susceptibility $\left[\chi^{(2)}\right]$ was quantified by the Maker Fringe technique using a $1550 \mathrm{~nm}$ intracavity optical parametric oscillator nanosecond laser operating at $30 \mathrm{~Hz}$ with a maximum impulsion of $100 \mu \mathrm{J}$ during a $20 \mathrm{~ns}$ pulse and with a spot size of $100 \mu \mathrm{m}$. Two sets of experiments were performed: $\theta$-scans (changing the incident angle with incident light polarized $\mathrm{p}$ or $\mathrm{s}$ and collecting p polarized light) and $\psi$-scans (at a fixed incidence angle, changing the incident polarization and collecting $\mathrm{p}$ or $\mathrm{s}$ polarized light). The experiment was calibrated with an $\alpha$-quartz $\mathrm{z}$-cut plate, which allowed for determination of absolute values for the second order susceptibility. The resulting spectra were fitted using a model described in Ref. 28. The SHG response depends on the incident intensity, the indices at $\omega$ and $2 \omega$ of both the bulk and the poled layer, the thickness of the poled layer, and the induced $\chi^{(2)}$. As all parameters are determined by independent techniques, the only parameters to fit are the $\chi^{(2)}$ tensor components.

\section{RESULTS}

\section{A. Physico-chemical properties and optimization of the poling parameters}

A series of six bpn-XNa glasses were synthetized with $\mathrm{X}=12$, $10,9,7,5$, and 3 as the nominal atomic percentage of sodium. The ratios between the other primary glass components $\mathrm{Nb} / \mathrm{P}$ and $\mathrm{Nb} / \mathrm{B}$ were kept constant as is shown in Table I where the as-batched compositions are summarized. The as-melted compositions were checked by EDS (Table I). A small deviation between the theoretical and measured composition was observed $(<10 \%$ deficiency in phosphorus). One has to mention that the deviation observed for boron is likely attributed to the difficulty in its analysis using EDS; hence, the measured $\mathrm{Nb} / \mathrm{B}$ ratio is off the expected value. However, the desired compositional evolution forming the basis of our study, that of sodium variation for a constant $\mathrm{Nb} / \mathrm{P}$ ratio, is retained.

The refractive index dispersions of the glasses are presented Fig. 1. The measured data are successfully fitted with the Cauchy dispersion law. One can see a regular increase of the refractive index with the decrease in sodium: at $1550 \mathrm{~nm}$, the index of bpn$12 \mathrm{Na}$ is $1.829( \pm 0.5 \%)$ and increases up to 1.924 for bpn $-3 \mathrm{Na}$. The densities reported in Table II follow the same trend as bpn-12Na presents a density of $3.580 \pm 0.006$ that regularly increases to $3.672 \pm 0.006$ for bpn-3Na. The glass transition temperatures $\left(\mathrm{T}_{\mathrm{g}}\right)$ are reported in Table II. With the decrease of the sodium content, one can see an increase of the $\mathrm{T}_{\mathrm{g}}$ as bpn-10Na shows a $\mathrm{T}_{\mathrm{g}}$ of $641 \pm 2{ }^{\circ} \mathrm{C}$ and bpn $-5 \mathrm{Na}$ shows $687 \pm 2{ }^{\circ} \mathrm{C}$. Note that bpn-3Na is off this trend and that the error bar on this measurement is larger than for other samples. This can be explained by the fact that this composition seems to be at the very border of the glass forming domain and thus the data for this sample must be treated with caution.

Regarding the optimization of the poling conditions, all treatments were performed under the same voltage, with the same sample thickness and the same electrode area. In order to obtain similarly efficient treatments on each sample, a question arises as to whether the temperature should be a fixed parameter or if it should

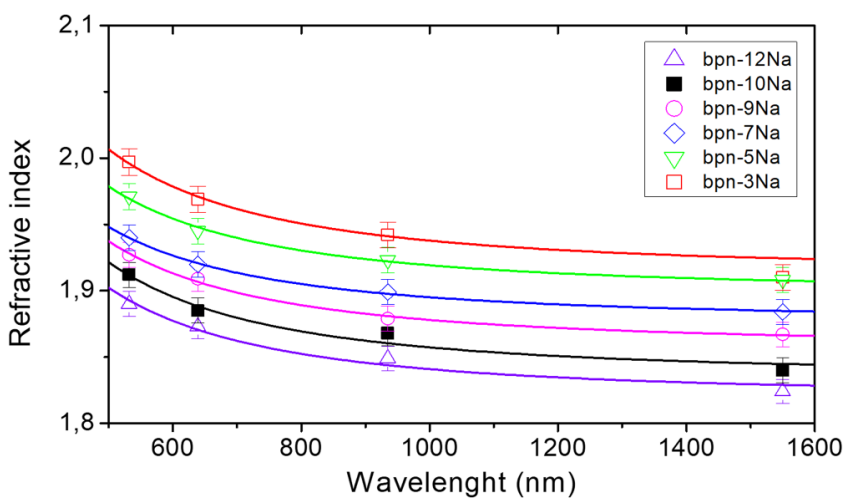

FIG. 1. Refractive index dispersion of bpn-XNa glasses prior to poling measured between 532 and $1550 \mathrm{~nm}$. The lines correspond to Cauchy fits [n $\left.(\lambda)=A+B / \lambda^{2}\right]$ 
TABLE II. Lines 1 and 2: DSC measured glass transition temperature $\left(T_{g}\right)$ and Archimedes method measured density for the different pristine samples prior to poling. Lines 3 and 4: poling temperatures chosen for each sample and the SIMS measured post-poled Na-depleted layer thickness to confirm that the treatment was efficient.

\begin{tabular}{lcccccc}
\hline \hline & $\mathrm{bpn}-12 \mathrm{Na}$ & $\mathrm{bpn}-10 \mathrm{Na}$ & $\mathrm{bpn}-9 \mathrm{Na}$ & $\mathrm{bpn}-7 \mathrm{Na}$ & $\mathrm{bpn}-5 \mathrm{Na}$ & $\mathrm{bpn}-3 \mathrm{Na}$ \\
\hline $\mathrm{T}_{\mathrm{g}}\left({ }^{\circ} \mathrm{C}\right)$ of the pristine bulk glasses & $\ldots$ & $641 \pm 2$ & $656 \pm 2$ & $678 \pm 2$ & $687 \pm 2$ & $681 \pm 10$ \\
Density of the pristine bulk glasses $\left(\mathrm{g} / \mathrm{cm}^{3}\right)$ & $3.580 \pm 0.006$ & $3.609 \pm 0.006$ & $3.640 \pm 0.006$ & $3.65 \pm 0.01$ & $3.664 \pm 0.007$ & $3.672 \pm 0.008$ \\
Poling temperature $\left({ }^{\circ} \mathrm{C}\right)$ & 230 & 250 & 265 & 287 & 296 & $\ldots$ \\
Post-poling Na-depleted layer thickness $(\mu \mathrm{m})$ & $1.53 \pm 0.05$ & $1.83 \pm 0.05$ & $2.06 \pm 0.05$ & $2.25 \pm 0.05$ & $2.6 \pm 0.1$ & $\ldots$ \\
\hline \hline
\end{tabular}

be adapted to the composition. Several tests were performed in order to investigate this question.

In a previous work, ${ }^{24}$ bpn-10Na was poled at a temperature close to $250^{\circ} \mathrm{C}$; the experiment was repeated successfully here with a measured current peaking at $0.32 \mathrm{~mA} / \mathrm{cm}^{2}$. When poled under these conditions, bpn-12Na (lower $\mathrm{T}_{\mathrm{g}}$ ) gave only poor results as a high current during poling (peaking at $1 \mathrm{~mA} / \mathrm{cm}^{2}$ ) led to a postpoling damaged surface that has lost its optical quality. At the opposite, the current was under the detection limit of our instrument (limit: $0.02 \mathrm{~mA} / \mathrm{cm}^{2}$ with the present electrode) for bpn-9Na (higher $\mathrm{T}_{\mathrm{g}}$ ). In other words, from bpn-10Na to bpn-9Na, the poling current decreases of at least one order of magnitude.

From the very distinct currents observed for different compositions poled at the same temperature, it appears clearly that the poling temperature should be adapted in order to obtain a similar mobility of the charge carriers for each poled samples. Based on these findings, we decided to pole bpn-10Na at $250{ }^{\circ} \mathrm{C}$ and to modify the poling temperature with respect to the change in $T_{g}$. These temperatures are reported in Table II. It has to be noted that no current or SHG signal was observed for bpn-3Na regardless of

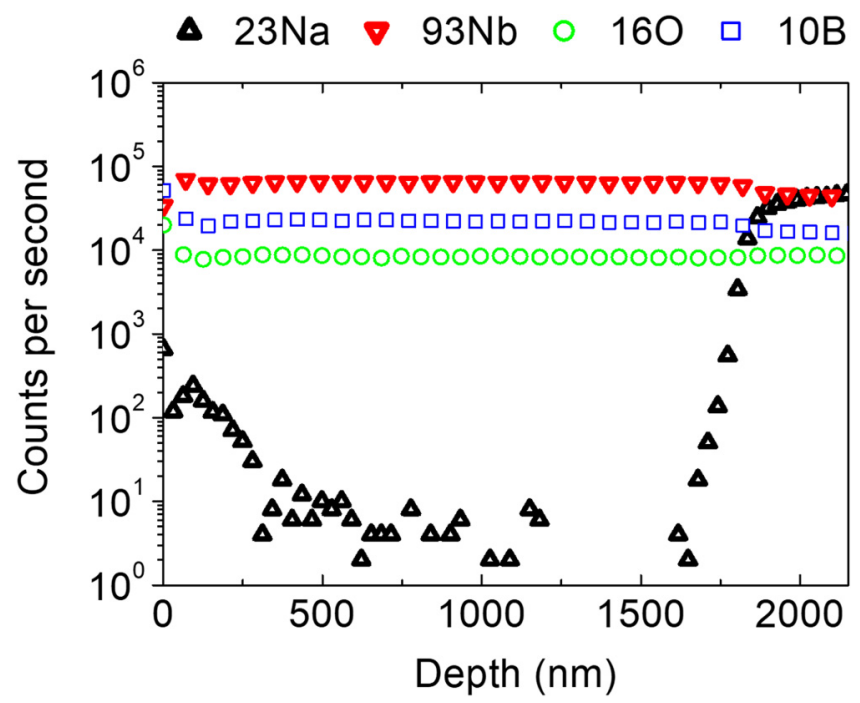

FIG. 2. Secondary ion mass spectroscopy (SIMS) depth profile of various glass constituents (phosphate not represented) of a bpn-10Na glass after poling. The $0 \mathrm{~nm}$ mark corresponds to the glass surface at the anode side. the poling temperature (tests performed up to $300^{\circ} \mathrm{C}$, which is the limit of our setup). Given these unexpected results and the fact that this composition is at the end of the glass stability region, we chose not to discuss those poling results in the rest of this paper.

The poling treatments are considered effective if sodium is depleted under the anode. To check the alkali migration for each glass, SIMS measurements were conducted in the depth of the poled zone. A typical concentration profile for the various constituents corresponding to the poled bpn- $10 \mathrm{Na}$ is presented in Fig. 2. One can observe a $1.83 \pm 0.05 \mu \mathrm{m}$ thick layer where sodium has been depleted while the other components remain unaffected by poling; this is consistent with previous studies. ${ }^{17}$ The poled layers' thicknesses measured using SIMS analysis are reported in Table III. The depleted layer thickness increases when the sodium content decreases (the one of bpn- $5 \mathrm{Na}$ is about 1.7 thicker than that of bpn-12Na). One could argue that different thicknesses reflect different poling efficiencies; however, as long as the poled layer thickness is a known parameter (measured by SIMS), side-by-side evaluation of the optical properties of the different samples is achievable.

\section{B. Structural study}

\section{Prior to poling}

The local structure of the glasses prior to and following poling will be discussed on the basis of a correlative Raman and infrared spectroscopy analysis. This analysis provides a means to successively study the niobium and the phosphorus ions and their specific organization within the glass networks. The influence of the sodium content on the structure is compared to previous works related to niobium oxide containing glasses. ${ }^{18}$ The stretching modes of the $\mathrm{Nb}-\mathrm{O}$ bonds are found in the $600-1000 \mathrm{~cm}^{-1}$ range. The ones attributed to $\mathrm{P}-\mathrm{O}$ bonds are in the $900-1300 \mathrm{~cm}^{-1}$ range. Niobium's polarizability being higher that phosphate's, the Raman spectra will rather give insights into the niobium network than the phosphate's; hence, the importance to combine two complementary techniques since the infrared will provide precious information on the phosphate groups arrangements. The Raman spectra between 300 and $1600 \mathrm{~cm}^{-1}$ of all the synthetized bulk glasses (from 3 to 12 at. \% of sodium) are shown in Fig. 3(a). The IR spectra are presented in Fig. 4.

Looking at the Raman response shown in Fig. 3(a), one can first notice that the less sodium in the glass, the stronger the Raman response is. For example, bpn-12Na's response is halved when compared to that of bpn-3Na at $700 \mathrm{~cm}^{-1}$. This is consistent with the increase of the refractive index when the sodium content goes down as observed in Fig. 1. To discuss the relative evolution of 
TABLE III. Molar weight, molar volume, niobium volume concentration, and molar polarizability for each as-melted sample.

\begin{tabular}{lccrrr}
\hline \hline Pristine glasses & bpn-12Na & bpn-10Na & bpn-9Na & bpn-7Na & bpn-5Na \\
\hline $\mathrm{M}_{\mathrm{w}}(\mathrm{g} / \mathrm{mol})$ & 27.99 & 28.59 & 28.79 & 29.53 & 30.29 \\
$\mathrm{~V}_{\mathrm{m}}\left(\mathrm{cm}^{3} / \mathrm{mol}\right)$ & 7.82 & 7.92 & 7.91 & 8.09 & 8.27 \\
{$[\mathrm{Nb}]_{\mathrm{V}}\left(\times 10^{22} / \mathrm{cm}^{3}\right)$} & 1.00 & 1.05 & 1.08 & 1.13 & 1.18 \\
$\alpha_{\mathrm{m}}\left(\times 10^{-24} \mathrm{~cm}^{3}\right)$ & 1.36 & 1.41 & 1.42 & 1.48 & 1.53 \\
\hline \hline
\end{tabular}

the Raman bands, the spectra have been normalized (by the area under the curve) in Fig. 3(b) and bpn-12Na's spectrum (highest sodium content) has been subtracted from the others [Fig. 3(c)]. The Raman difference spectrum allows for a direct evaluation of the influence of the sodium content. The $\mathrm{Nb}-\mathrm{O}$ stretching modes region can be divided into three domains. Between 600 and $750 \mathrm{~cm}^{-1}$, the $\mathrm{Nb}-\mathrm{O}-\mathrm{Nb}$ successions connecting $\mathrm{NbO}_{6}$ octahedrons are found in a three-dimensional (3D) network. At $600 \mathrm{~cm}^{-1}$, the network is perfectly regular, as observed in perovskite crystalline phases such as $\mathrm{NaNbO}_{3} .{ }^{29}$ The more the band shifts to higher energy, the more distorted the network is. The 750$860 \mathrm{~cm}^{-1}$ region corresponds to the $\mathrm{Nb}-\mathrm{O}-\mathrm{P}$ successions connecting niobate octahedrons and phosphate tetrahedrons. Finally, at higher energies, $860-1000 \mathrm{~cm}^{-1}$, the $\mathrm{Nb}-\mathrm{O}$ bond is the most covalent as the oxygen is involved in an ionic bond with $\mathrm{Na}^{+}$. A regular decrease of this band is observed when going from bpn-12Na to bpn-3Na; this is consistent with the lowest sodium content and then the lowest formation of $\mathrm{Nb}-\mathrm{O}-\mathrm{Na}$ bonds. The band attributed to the $\mathrm{Nb}-\mathrm{O}-\mathrm{P}$ bridges follows a similar trend; the interconnections between the niobium and the phosphorus ions are thus modified. These two behaviors go along with a blue shift of the band attributed to the $\mathrm{Nb}-\mathrm{O}-\mathrm{Nb}$ succession meaning that when going from bpn-12Na to bpn-3 $\mathrm{Na}$, the $3 \mathrm{D}$ niobate network is more and more distorted.

Let us now discuss the evolution of the phosphorus ions' environment based on the absorbance spectra in Fig. 4. Focusing on the absorbance spectrum of bpn-12Na, the region between 900 and $1300 \mathrm{~cm}^{-1}$ is clearly composed of three contributions that were studied in a previous work. ${ }^{24}$ Both high and low wavenumber components centered at 900 and $1120 \mathrm{~cm}^{-1}$ are attributed to pyrophosphate (dimers) entities: asymmetric stretching modes of $\mathrm{P}-\mathrm{O}-\mathrm{P}$ bridges and $\left(\mathrm{PO}_{3}\right)^{2-}$ terminating entities, respectively. The band centered on $1000 \mathrm{~cm}^{-1}$ corresponds to the asymmetric stretching modes of orthophosphate (monomers) entities $\left[\right.$ or $\left(\mathrm{PO}_{4}\right)^{3-}$ entities]. Thus, the phosphate groups of bpn-12Na are composed of a mix of these two entities. When the sodium content decreases, one can see a decrease of the contribution of the pyrophosphate entities in favor of the orthophosphate groups with a striking heightening of the band centered on $1000 \mathrm{~cm}^{-1}$. Consequently, the less the sodium in the glass, the more the phosphorus is under the monomer form and dispersed within what we can call a "niobate skeleton" formed from corner shared $\mathrm{NbO}_{6}$ octahedrons.

Overall, when the sodium content decreases, a distortion of the niobate network is observed. In a structure like the $\mathrm{NaNbO}_{3}$ perovskite, ${ }^{29}$ presenting a unique sharp mode at $600 \mathrm{~cm}^{-1}$, the network is perfectly regular and a sodium atom occupies every cubic sites formed by the $\mathrm{NbO}_{6}$ octahedrons. If sodium is removed from these sites, it is clear that the network cannot keep its organization due to charge compensation issues and it will undergo a distortion to compensate for this loss. A similar behavior is most probably observed here. Another factor that can be at the origin of this change of structure is the fact that the phosphorus is now present in smaller entities

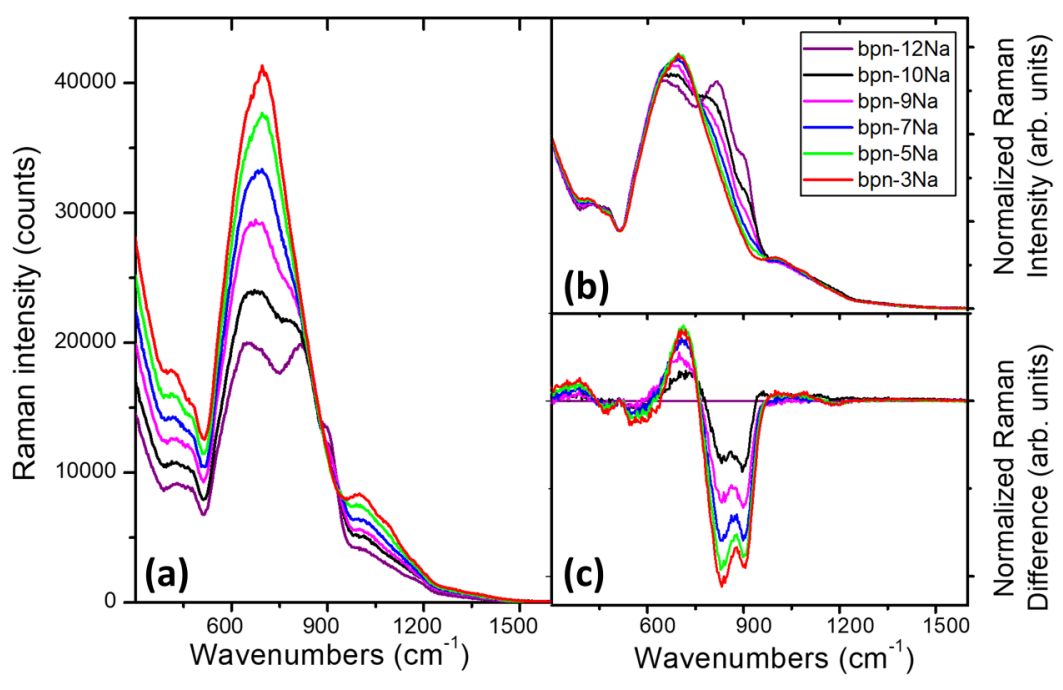

FIG. 3. Raman response as a function of the sodium content. (a) Raman spectra of the different samples collected with the same objective and the same laser intensity. (b) Normalized (by the area under the curve) Raman spectra. (c) Different Raman spectra corresponding to the spectrum of the highest sodium content glass (bpn-12Na) subtracted from the other ones. 


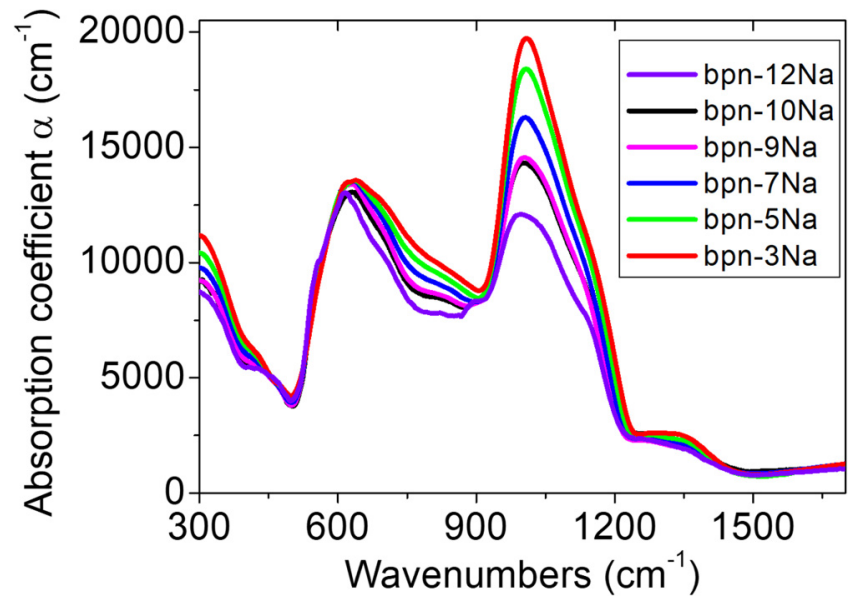

FIG. 4. Absorption coefficients obtained by the reflectance spectra KramersKrönig transformation.

that can be more imbricated in the niobate network than the pyrophosphate ones, which could lead to a larger distribution of the Nb$\mathrm{O}$ bond length in the glassy network.

\section{Thermally poled glasses}

Glass samples poled with a platinum electrode under $800 \mathrm{~V}$ at poling temperatures adapted to their composition and thermal properties were shown previously (see Table I). To assess the structural variations induced by the poling treatment, the samples were cut and analyzed on their cross section. Correlative Raman/SHG cartographies have been realized. Since during poling sodium is the mobile element, ${ }^{17}$ the highest contrast between the poled layer and the bulk is obtained for the highest initial sodium content. Thus, the poled bpn-12Na glass will be looked into to illustrate the effect of poling. In Fig. 5(a), the normalized Raman spectra of the poled bpn-12Na close to (in red) and farther from (in black) the anode surface are represented. These zones correspond respectively to the poled layer and the region unaffected by poling. To elucidate the spectral variations representative of structural changes induced by poling, the spectrum of the sodium containing region (far from the anode and unaffected by poling) was subtracted from the one of the poled layer [Fig. 5(b)]. This follows the same methodology employed in Fig. 3(c). The resulting Raman difference spectrum is in good agreement with previous works. ${ }^{30,31}$ The spatial evolution of three representative Raman bands is shown in Fig. 5(c) (green, red, and blue lines) side by side with the SHG profile (in black).

First, one can see that the structural variations are confined in a layer presenting a thickness lower than $2 \mu \mathrm{m}$. Note that the size of the laser spot being of about $1 \mu \mathrm{m}$, measuring the thickness of the poled layer with this technique, is not optimal (resolution: $\pm 0.5 \mu \mathrm{m}$ ). Nevertheless, this measure is consistent with the SIMS measurements reported in Table II $(1.53 \pm 0.05 \mu \mathrm{m})$. The structural changes are co-localized with the SHG response, which is also consistent with a previous work. ${ }^{6}$ Now, looking at the characteristic bands discussed previously and at the spatial profile of their intensity under the anode [Figs. 5(b) and 5(c)], one can make the following statements: (1) The intensity profile (in red) of the band at $700-750 \mathrm{~cm}^{-1}$ evidences a distortion of the niobate network in the layer under the anode. (2) The profiles of the bands between 750 and $950 \mathrm{~cm}^{-1}$ in blue show a decrease in the same layer of the spectral region corresponding to both phosphate dimers and sodium related entities. This shows a decrease of the number of pyrophosphate and confirms the departure of sodium upon poling in the sub-anodic layer. (3) Another band at $1550 \mathrm{~cm}^{-1}$ appears in the poled layer, which is attributed to molecular oxygen trapped in the glass matrix. ${ }^{19,20,32}$ This is the trace of the charge compensation mechanisms from negative charge carriers and their motion (anionic or electronic ${ }^{20,32,33}$ ) occurring during poling.

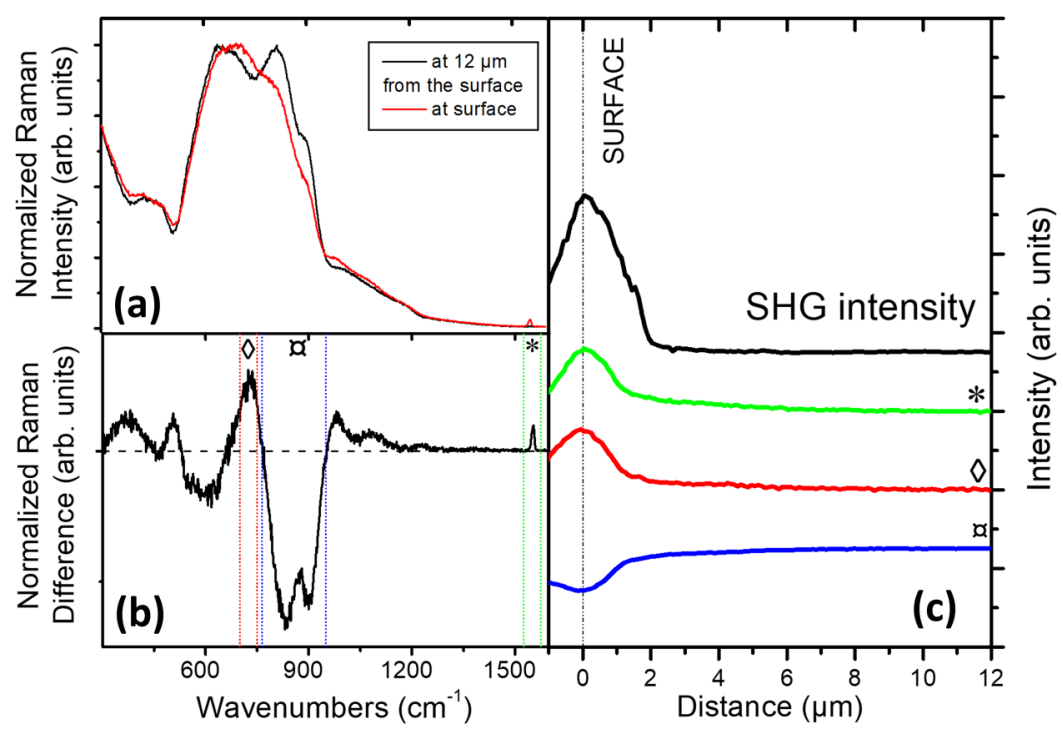

FIG. 5. Raman/SHG correlated microscopy on the cross section of a poled bpn-12Na sample. (a) Normalized Raman spectra far from the surface in black and at the anode side in red. (b) Raman difference (red spectrum minus black spectrum). The horizontal black dotted line corresponds to the zero. (c) In blue, red, and green, spatial evolution of the Raman bands selected in (b) by the blue, red, and green dotted lines; the symbols also show the correspondence between the integration bounds and the corresponding profiles. In black, the SHG intensity profile is represented. The relative intensities were modified for display reasons. The zero mark corresponds to the surface of the poled glass (on the anode side). 


\section{Influence of poling on linear and nonlinear optical properties}

Thermal poling modifies the optical properties of glasses: SONL response is induced in a poled layer and goes along with a modification of the linear (refractive index) optical properties. The influence of the sodium content on these changes is evidenced in this section.

\section{Linear properties}

Micro-IR reflectance spectra of the bpn-9Na sample are shown in Fig. 6. The spectra were acquired outside of the poled area (in blue) and within the poled area (in black) between 600 and $7000 \mathrm{~cm}^{-1}$. The two peaks at 600 and $1000 \mathrm{~cm}^{-1}$ are attributed to $\mathrm{Nb}-\mathrm{O}$ and $\mathrm{P}-\mathrm{O}$ bonds stretching vibrations and were discussed in Fig. 4. The region of interest in this section of the paper is the one free of absorption above $1500 \mathrm{~cm}^{-1}$. In this region, one can see that thermal poling induces a decrease of the reflectivity and the appearance of fringes. The interference fringes confirm that poling induces a layer of different refractive index than the bulk's, while the decrease in reflectivity shows a lowering of the refractive index. It is considered here that the index change is strongly linked to the sodium depletion layer observed by SIMS and reported in Table II. To quantify the index change induced by poling, we have followed the procedure described in Ref. 6 . We have simulated the fringes between 4000 and $7000 \mathrm{~cm}^{-1}$ with a model of two or three layers depending on the sample to obtain a step-like profile of the index. The global thickness of the layers was forced to correspond with the sodium-depleted layer measured in SIMS. The simulation obtained for the poled bpn-9Na is presented in the inset of Fig. 6 in red. A good agreement between the experiment and the simulation is obtained with an index change $\Delta \mathrm{n}$ (=poled-bulk) of $-0.022 \pm 10 \%$.

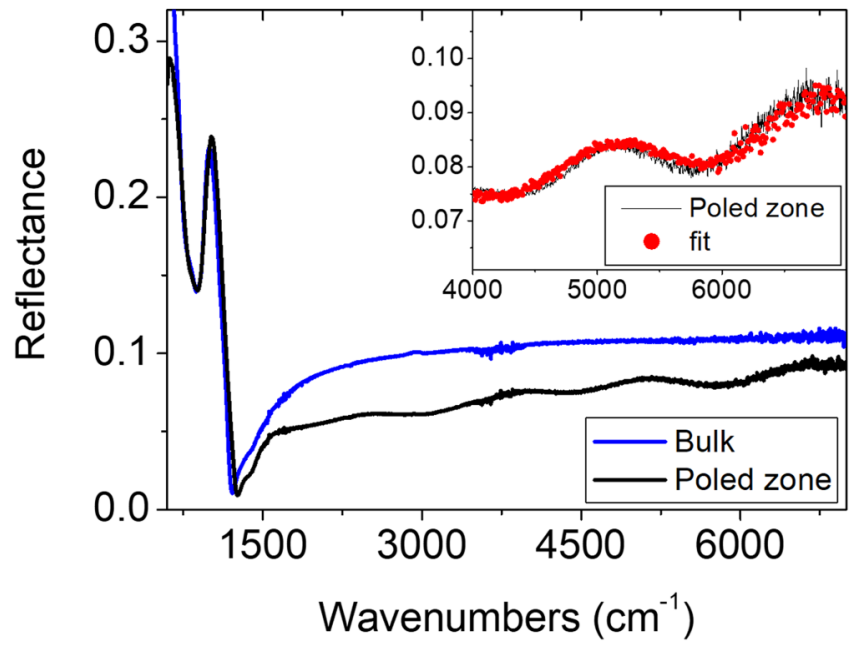

FIG. 6. Micro-IR reflectance spectra measured outside (blue) and inside (black) the poled area of a thermally poled bpn-9Na. (Inset) Measured (black line) and calculated (red dots) high frequency reflectance profiles.

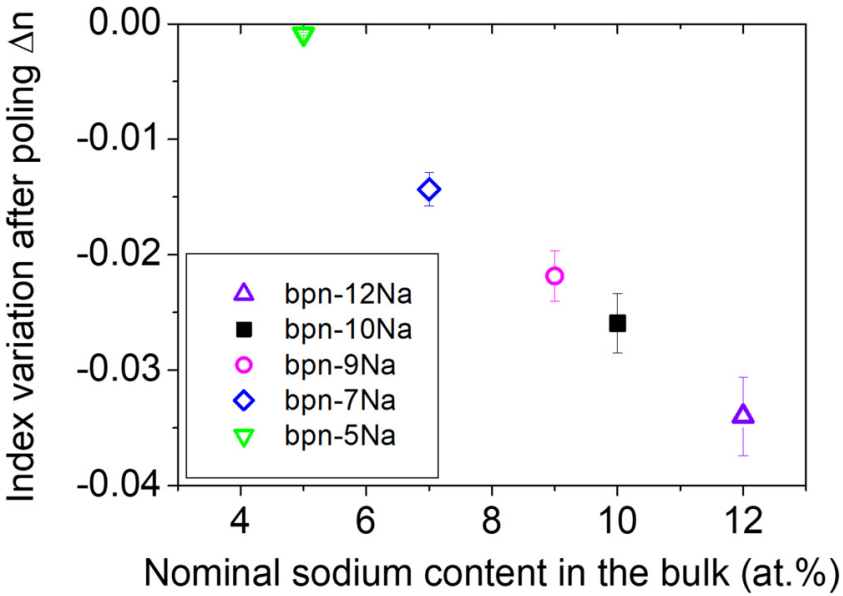

FIG. 7. Index variation between the bulk glass and the poled area (the error bar is $10 \%$ ) as a function of the initial sodium content obtained by fitting of the reflectance spectra in the region $4000-7000 \mathrm{~cm}^{-1}$.

Figure 7 illustrates the index change calculated for each poled sample as a function of the initial sodium content. A range of index changes going from -0.0009 for bpn-5Na to -0.034 for bpn-12Na are obtained (error: 10\%). The higher the initial sodium content is, the bigger (in absolute value) the index change is. One can also see a linear evolution of the $\Delta \mathrm{n}$ with the sodium content; this confirms our hypothesis that the glass' initial sodium content can be used as a lever to control the post-poled refractive index change.

\section{Nonlinear properties}

To quantify the second order susceptibility induced by thermal poling, a SHG ellipsometric technique was used: the Maker fringe analysis. Characteristic scans as a function of the incidence angle $(\theta$-scan) and of the polarization ( $\psi$-scans) are presented in Figs. 8(a) and 8(b). They correspond with the response of the poled bpn-9Na.

In previous works on BPN glasses, ${ }^{11,17,18}$ the model employed to describe the origin of the SONL response after poling is that of an electro-optic effect (electric field induced second harmonic or EFISH). This means that the induced second order susceptibility is $\chi^{(2)}=3 \mathrm{E} \cdot \chi^{(3)}$. In this model, $\chi^{(2)}$ is induced in a layer of a given thickness presenting $\mathrm{C}_{\infty \mathrm{v}}$ symmetry. Assuming Kleinman's conditions, which is being far from any absorptions, the resulting $\chi^{(2)}$ tensor presents two non-zero terms linked by the following equation: ${ }^{34} \chi_{\mathrm{zxx}}^{(2)}=1 / 3 \chi_{\mathrm{zzz}}^{(2)}$. The SHG response is a function of several parameters: the refractive indices at $\omega$ and $2 \omega$ of the poled layer and the bulk, the thickness of the poled layer, the second order susceptibility, and the incident intensity at $\omega$. The indices of the bulk were measured by the Brewster angle technique [Fig. 1(b)], the one of the poled layer was evaluated previously in this section (Fig. 7), the thicknesses were measured by SIMS (Table III), and the incident intensity is recorded during the Maker fringe measurements. 

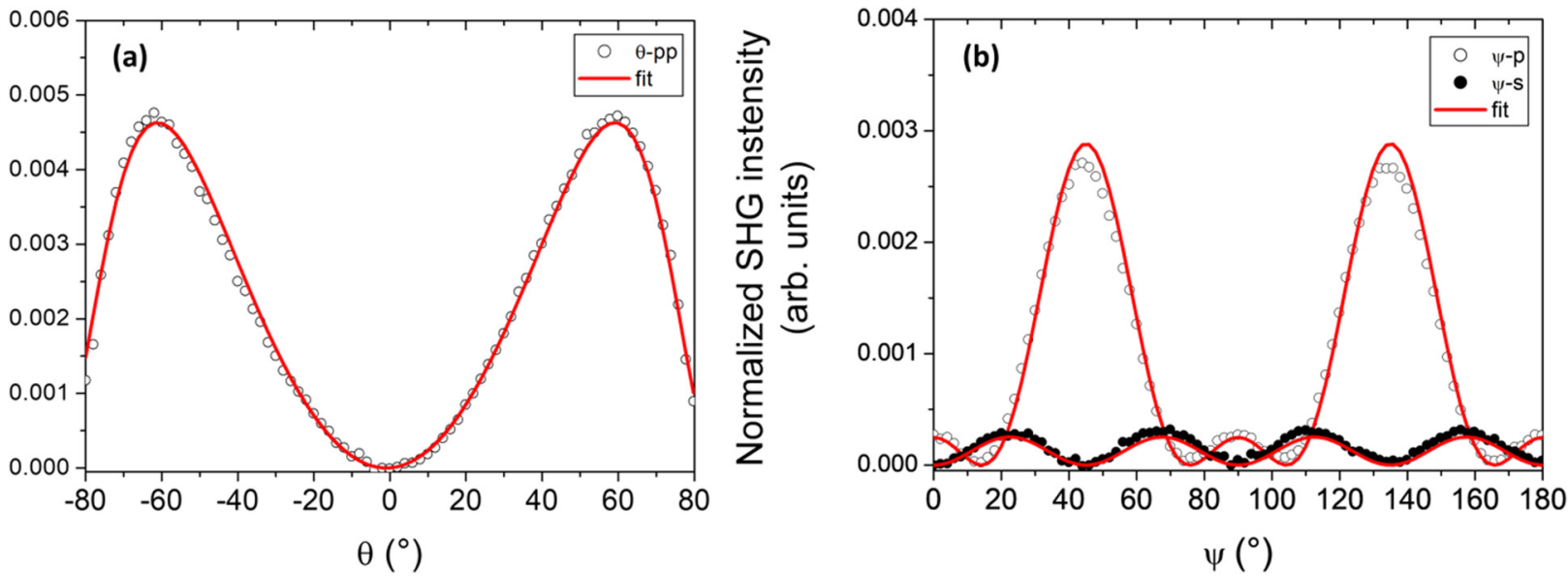

FIG. 8. Maker Fringe analysis for thermally poled bpn-9Na. (a) P-P normalized transmitted SHG intensity as a function of the incidence angle. (b) P- (open dots) and S(black dots) normalized transmitted SHG intensity as a function of the incident polarization. On both plots, the dots correspond to the experimental points and the red lines are the calculated values.

Overall, the only unknown parameter here is the second order susceptibility making simulations very robust. The calculated scans for bpn-9Na are presented in Fig. 8 (red lines); they overlap well with experimental measurements validating the EFISH model. A value of $2.1 \pm 0.1 \mathrm{pm} / \mathrm{V}$ was found for the $\chi_{\mathrm{zzz}}^{(2)}$ component of bpn-9Na's second order susceptibility tensor, which is coherent with previous works on similar compositions. ${ }^{17,18}$

Figure 9 presents the evolution of $\chi_{\mathrm{zzz}}^{(2)}$ as a function of the initial sodium content. In bpn- $5 \mathrm{Na}$, a $\chi_{\mathrm{zzZ}}^{(2)}$ of $2.5 \pm 0.1 \mathrm{pm} / \mathrm{V}$ was induced, while for bpn-10Na, it was of $1.94 \pm 0.15 \mathrm{pm} / \mathrm{V}$. It is difficult from these values to comment on the behavior of the SONL response with the sodium content as the evolution is not

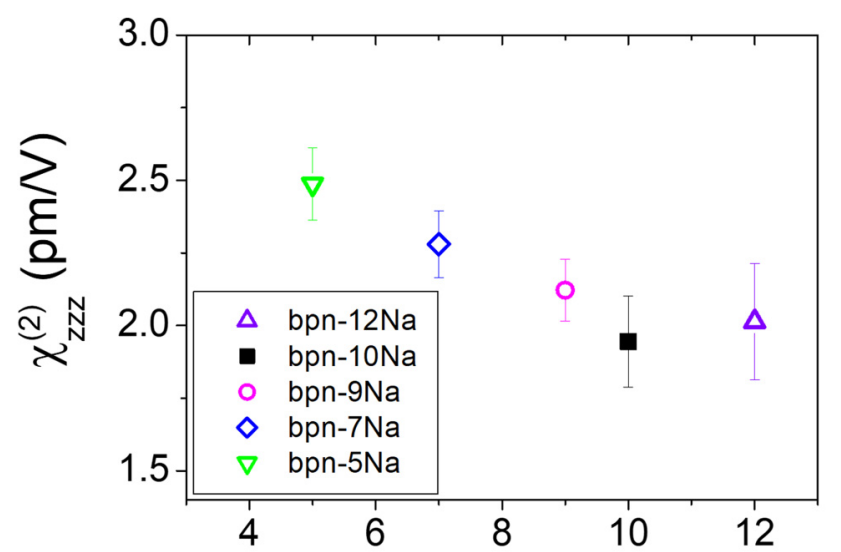

Nominal sodium content in the bulk (at.\%)

FIG. 9. Fitted second order optical susceptibility $\chi_{\text {zzz }}^{(2)}$ component for the different glass compositions. exactly monotonous. However, taking into account the error bars, the general tendency is an increase of $\chi^{(2)}$ for the lower contents of sodium with an increase of $30 \%$ between bpn-10Na and bpn-5Na.

\section{DISCUSSION}

In the present study, the sodium content was decreased by two different ways: (1) by choosing the initial composition of the glass (from bpn-12Na to bpn-3Na) and (2) through poling (all sodium being removed from the poled layer, cf. Fig. 2). This variation was carried out to examine the impact of the as-melted glass' sodium content in changing the glass' post-poled structure and resulting optical properties. Let us first compare the influence of these two strategies on the structural rearrangements.

Looking at the Raman difference (post-poled minus bulk) spectrum [Fig. 5(b)] against the Raman difference spectra (sodium poor minus sodium rich bulk glasses) [Fig. 3(c)], it is striking that the structural variations in both cases are analogous. Only do these two responses differ on the appearance of molecular oxygen, which is a poling-only mechanism. This means that the glass matrix is flexible enough so that, whether the sodium content is decreased in the glass composition (through high melting temperature) or by thermal poling (at low temperature assisted with an electric field), the resulting structural rearrangements are equivalent. In other words, thermal poling is a tool to obtain, on a few micrometers thick layer, a glass of the same structure and composition as a niobium-borophosphate glass without sodium. It is important here to note that, as mentioned in Sec. I of this paper, the synthesized bpn- $3 \mathrm{Na}$ is at the border of the classical glass forming domain; hence, it appears that a BPN glass without sodium is completely out of this domain. In consequence, thermal poling could be considered a tool to obtain new glassy structures/materials that could not be reached using a classical glass synthesis route. 
From Fig. 1, one can see that the index of the bulk glasses increases when the sodium content decreases. Conversely, from Figs. 6 and 7, a drop of the index is observed after poling, that is, when sodium is removed. We get here a substantial inconsistency in our reasoning: on the one hand, similar composition and structure are observed whether the sodium content is decreased by tuning the composition or by thermal poling, and, on the other hand, the refractive index evolutions in these two cases are diametrically opposed. To understand these contradictory behaviors, let us first discuss the origin of index variation in the bulk glasses before poling.

Writing the composition of each bpn-XNa glass as $\mathrm{B}_{\mathrm{a}} \mathrm{P}_{\mathrm{b}} \mathrm{Nb}_{\mathrm{c}} \mathrm{Na}_{\mathrm{X}} \mathrm{O}_{\mathrm{d}}$ with $\mathrm{a}, \mathrm{b}, \mathrm{c}, \mathrm{d}$, and $\mathrm{X}$, the theoretical atomic percentage of each element as reported in Table I, one can calculate the corresponding molar weight $\left(\mathrm{M}_{\mathrm{W}}\right)$. From the densities $(\rho)$ reported in Table II, the molar volume $V_{m}$ is obtained $\left(V_{m}=M_{w} / \rho\right)$.
This directly gives access to the number of niobium atoms per unit of volume $\left([\mathrm{Nb}]_{\mathrm{V}}=\mathrm{cN}_{\mathrm{A}} / \mathrm{V}_{\mathrm{m}}\right.$ with $\mathrm{N}_{\mathrm{A}}$ being the Avogadro number). These results are summarized in Table III.

In Fig. 10(a), the refractive index at $1550 \mathrm{~nm}$ (n) is plotted against the number of niobium atoms per unit of volume; the refractive index clearly increases linearly with the niobium volume concentration. The relative Raman intensity follows a similar trend as can be seen in Fig. 10(b). It is important to note here that the Raman spectra were measured under the same experimental conditions (objective, laser power). For simplification, we have neglected changes in the collection solid angle and reflection losses linked to index variations form one sample to another, which induce an error in the Raman intensity measurements estimated at $10 \%$. In this error range, the evolution of the relative Raman intensity with the niobium volume content is retained; it increases linearly.
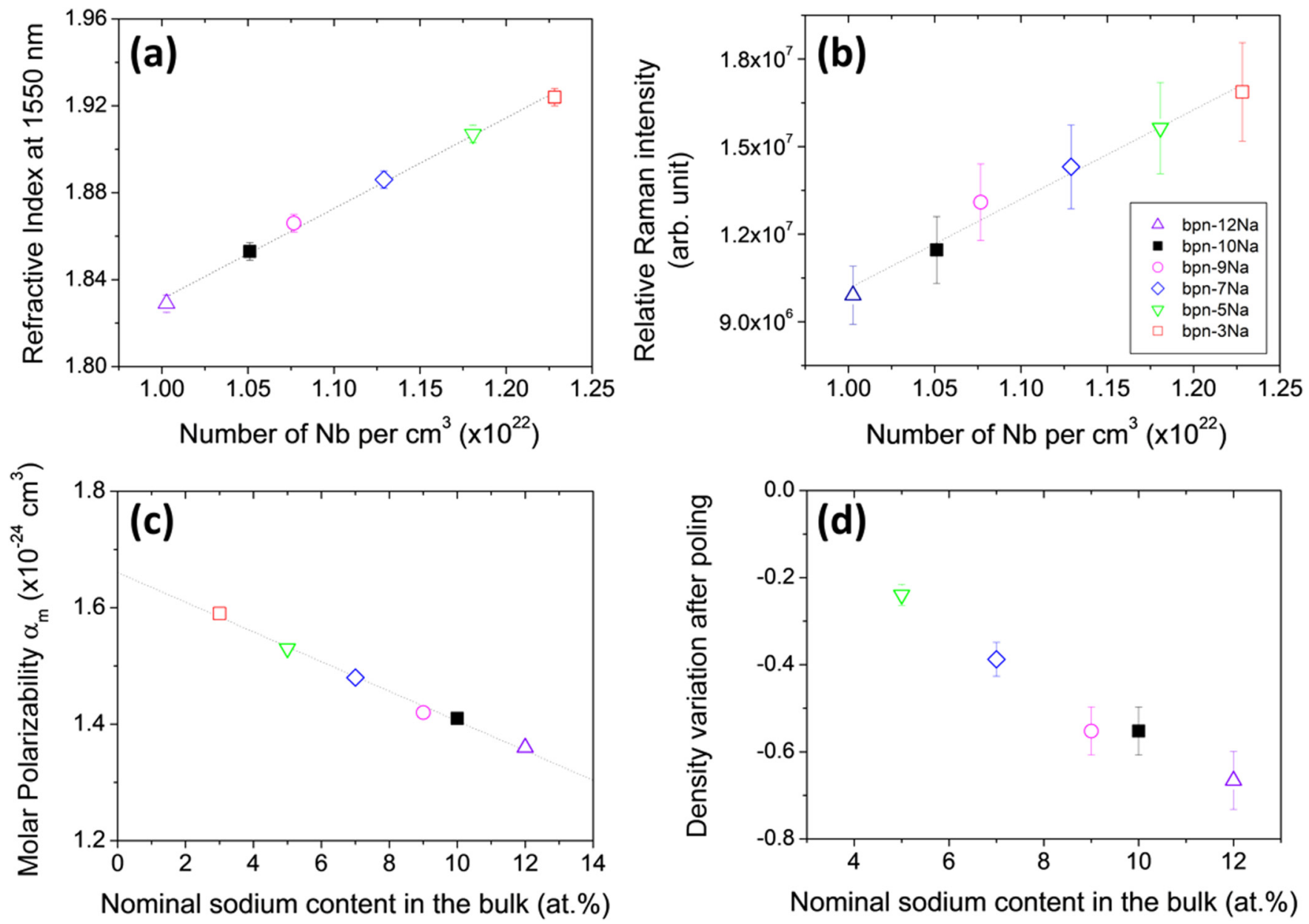

FIG. 10. (a) The refractive index at $1550 \mathrm{~nm}$ and (b) the relative Raman intensity between 300 and $1600 \mathrm{~cm}^{-1}$ for each sample (before poling) as a function of the niobium volume concentration. The dotted lines correspond to linear fits. (c) The calculated molar polarizability for each glass as a function of the nominal sodium content. The linear fit (dotted lines) allows us to estimate the polarizability of a glass without sodium. (d) The density variation after poling (calculated density of the poled zone minus the density of the pristine glass). The color code is unchanged throughout the whole figure. 
TABLE IV. Refractive index at $1550 \mathrm{~nm}$, molar volume, molar weight, and density of the poled layer for each sample.

\begin{tabular}{|c|c|c|c|c|c|}
\hline Poled glasses & bpn-12Na & bpn-10Na & bpn-9Na & bpn-7Na & bpn-5Na \\
\hline Index (at $1550 \mathrm{~nm}$ ) & 1.795 & 1.827 & 1.844 & 1.872 & 1.906 \\
\hline $\mathrm{V}_{\mathrm{m}}\left(\mathrm{cm}^{3} / \mathrm{mol}\right)$ & 9.84 & 9.56 & 9.42 & 9.21 & 8.96 \\
\hline $\mathrm{M}_{\mathrm{w}}(\mathrm{g} / \mathrm{mol})$ & 26.68 & 29.22 & 29.36 & 30.03 & 30.67 \\
\hline Density & 2.914 & 3.057 & 3.117 & 3.262 & 3.424 \\
\hline
\end{tabular}

Niobium is the heaviest element contained in these glasses; it also presents an extended electronic cloud that is highly polarizable. These aspects explain the fact that niobium contributes highly to the polarizability, refractive index and so to the Raman response intensity as well as to the hyperpolarizability.

If we make the assumption that there is no contraction of the glass upon poling, the niobium volume concentration is unchanged after the treatment. This explains why an increase of the index is not observed in the poled layer. However, it is not enough to explain a decrease of this quantity. To understand, we need to access to a key parameter: the density of the poled layer.

The molar polarizability $\alpha_{\mathrm{m}}$ of each bulk glasses was calculated using the Lorentz-Lorenz relationship,

$$
\alpha_{\mathrm{m}}=\frac{3 \mathrm{~V}_{\mathrm{m}}}{4 \pi \mathrm{N}_{\mathrm{A}}} \frac{\mathrm{n}^{2}-1}{\mathrm{n}^{2}+2} .
$$

These values are reported in Table III and plotted with respect to the sodium content on Fig. 10(c). The linear evolution allows us to estimate the molar polarizability of a glass presenting zero percent of sodium. The refractive indices change of the poled zones were estimated in Fig. $7(\Delta \mathrm{n}=$ poled-bulk). Consequently, by reversing Eq. (1), it is possible to calculate for each bpn-XNa glass the molar volume of their poled zone. After poling, the depleted layer composition can be written as $\mathrm{B}_{\mathrm{a}} \mathrm{P}_{\mathrm{b}} \mathrm{Nb}_{\mathrm{c}} \mathrm{O}_{\mathrm{d}}$; for each sample, one can calculate the molar weight of the poled zone and deduce the density of the poled layer $\left(\rho=\mathrm{M}_{\mathrm{w}} / \mathrm{V}_{\mathrm{m}}\right)$. The results of these calculations are reported in Table IV.

The variation of the density after poling as a function of the initial sodium content in the bulk is plotted [Fig. 10(d)]. Compared to the pristine glass, the density decrease is about $6 \%$ for bpn- $5 \mathrm{Na}$ and up to $18 \%$ for bpn-12Na. The variation of the density follows the same trend as the refractive index change: the higher the initial sodium content is, the bigger the variation is. Overall, the refractive index variation observed during poling is mainly due to a modification of the density rather than a modification of the composition or structure. It is closely linked to a drop of the density of the material when sodium is removed. The magnitude of the change is more important when a bigger quantity of sodium is removed.

Let us now focus on the evolution of the SONL response with respect to the sodium content. As introduced in Sec. III C 2, $\chi^{(2)}$ tends to increase when the sodium content decreases. One can wonder what parameters play a role in this evolution. The Maker fringe analysis has shown that for all samples, the induced $\chi^{(2)}$ was originating from an EFISH process (pure dipolar electro-optical contribution). This means that $\chi^{(2)}$ can be written as $\chi^{(2)}=3 \mathrm{E}_{0} \cdot \chi^{(3)}$. In other words, two parameters affect the magnitude of the second order susceptibility: the implemented electric field $\left(\mathrm{E}_{0}\right)$ and the third order susceptibility.

One can notice that the thickness of the poled layer is larger when the initial sodium content is smaller (Table II). As the same field is applied to all samples in the first place (note that this is independent of the temperature), spreading out the internal field on a larger distance makes the post-poling resulting field smaller. It is thus smaller for lower content of sodium; as an example, the implemented field is smaller in bpn-5Na glass than in bpn- $12 \mathrm{Na}$ glass.

The absolute value of $\chi^{(3)}$ was not measured in this study; nevertheless, we have information on its relative evolution as it behaves similar to the Raman intensity. ${ }^{35}$ When the initial sodium content decreases (i.e., when the number of niobium per volume increases), $\chi^{(3)}$ should increase, which is also confirmed by the evolution of the refractive index and the polarizability. Furthermore, one needs to keep in mind that the $\chi^{(3)}$ we are interested in is the one of the poled layer; thus, just like the linear refractive index, it should be impacted by the density decrease after poling. The density decrease is smaller in the case of glasses with low sodium content [Fig. 10(d)]. To illustrate the previous statements, let us consider bpn-12Na and bpn $-5 \mathrm{Na} . \chi^{(3)}$ of bpn-5Na glass prior to poling is higher than bpn-12Na glass'. Post poling, the density decrease is more important in the case of bpn-12Na glass. Thus, if both $\chi^{(3)}$ decrease upon poling, relatively the one in the poled layer of bpn-5Na glass is bigger than the one of bpn-12Na for two reasons: composition and being less subject to density change.

Overall, the evolution of $\chi^{(3)}$ due to both the composition and the density change tends to increase $\chi^{(2)}$ when the sodium content decreases. This factor is partially compensated by the lower internal field implemented for the lowest sodium contents as expected considering the slight variation in the poled layer thicknesses. As a low increase of $\chi^{(2)}$ is observed when going from bpn-12Na to bpn$5 \mathrm{Na}$, we can conclude that $\chi^{(3)}$ is the most influenced parameter but its influence is tempered by the internal electric field lowering.

\section{CONCLUSION}

The side by side monitoring of the influence of the sodium decrease on the structure (1) from bpn-12Na to bpn-3Na and (2) through thermal poling was realized. It brought evidence to consider poling as a tool to obtain on a few micrometers thick layer a glass presenting the same structure and composition as bpn- $0 \mathrm{Na}$ ( 0 at. \% of sodium) that is not achievable through the classical melting process. We have shown that if, regarding the structure and composition, this layer presents the attributes of a glass with low sodium content, it is not the case of its optical properties. 
The origin of the index decrease upon poling was discussed; a variation of the density function of the initial sodium content was shown to be the main factor influencing the index change before the structure or the composition. The influence of the sodium content on the induced SONL response was also discussed. Two parameters turned out to play a role in this evolution: the third order susceptibility $\chi^{(3)}$ and the internal electric field. When the initial sodium content decreases, $\chi^{(3)}$ tends to increase (higher niobium volume concentration and lower density change for the glasses with low initial sodium content), while the internal field compensates for this effect with lower implemented fields when the sodium content is low. Overall, we have confirmed that the initial sodium content was a lever to trigger the poling-induced optical functionalities (index change and SONL response) and we have proposed comprehensive explanations as of how the sodium content influenced these functionalities.

\section{AUTHORS' CONTRIBUTIONS}

The manuscript was written through contributions of all authors. All authors have given approval to the final version of the manuscript.

\section{ACKNOWLEDGMENTS}

The authors gratefully acknowledge the financial support of IdEx Bordeaux (Cluster of Excellence LAPHIA and the allocated grant referred to as ANR-10-IDEX-03-03), the IdEx Bordeaux Visiting Scholar program, and the CNRS project EMERGENCE @INC2019. This project has received funding from the European Union's Horizon 2020 research program under the Marie Skłodowska-Curie Grant Agreement No. 823941 (FUNGLASS). This work was partially supported by the French RENATECH network. The authors would like to thank Mikhail Klimov at the Material Characterization Facility (MCF) at UCF for conducting the SIMS measurements as well as Michel Lahaye at the Placamat Facilities at the University of Bordeaux for the EDS measurements. The authors also want to acknowledge the LAAS-CNRS Laboratory in Toulouse for the fabrication of the electrodes.

\section{DATA AVAILABILITY}

The data that support the findings of this study are available from the corresponding author upon reasonable request.

\section{REFERENCES}

${ }^{1}$ A. Lepicard, T. Cardinal, E. Fargin, F. Adamietz, V. Rodriguez, K. Richardson, and M. Dussauze, J. Phys. Chem. C 119, 22999 (2015).

${ }^{2}$ A. Lepicard, T. Cardinal, E. Fargin, F. Adamietz, V. Rodriguez, K. Richardson, and M. Dussauze, Chem. Phys. Lett. 664, 10 (2016).

${ }^{3}$ F. Lind, D. Palles, D. Möncke, E. I. Kamitsos, and L. Wondraczek, J. Non-Cryst. Solids 462, 47 (2017).

${ }^{4}$ A. N. Kamenskii, I. V. Reduto, V. D. Petrikov, and A. A. Lipovskii, Opt. Mater. 62, 250 (2016).

${ }^{5}$ I. Reduto, A. Kamenskii, P. Brunkov, V. Zhurikhina, Y. Svirko, and A. Lipovskii, Opt. Mater. Express 9, 3059 (2019).
${ }^{6}$ M. Dussauze, E. I. Kamitsos, E. Fargin, and V. Rodriguez, Chem. Phys. Lett. 470, 63 (2009).

${ }^{7}$ A. Lepicard, F. Bondu, M. Kang, L. Sisken, A. Yadav, F. Adamietz, V. Rodriguez, K. Richardson, and M. Dussauze, Sci. Rep. 8, 7388 (2018).

${ }^{8}$ A. L. R. Brennand and J. S. Wilkinson, Opt. Lett. 27, 906 (2002).

${ }^{9}$ R. A. Myers, N. Mukherjee, and S. R. Brueck, Opt. Lett. 16, 1732 (1991).

${ }^{10}$ Y. Quiquempois, G. Martinelli, P. Dutherage, P. Bernage, P. Niay, and M. Douay, Opt. Commun. 176, 479 (2000).

${ }^{11}$ M. Dussauze, T. Cremoux, F. Adamietz, V. Rodriguez, E. Fargin, G. Yang, and T. Cardinal, Int. J. Appl. Glass Sci. 3, 309 (2012).

${ }^{12}$ B. Ferreira, E. Fargin, B. Guillaume, G. Le Flem, V. Rodriguez, M. Couzi, T. Buffeteau, L. Canioni, L. Sarger, G. Martinelli, Y. Quiquempois, H. Zeghlache, and L. Carpentier, J. Non-Cryst. Solids 332, 207 (2003).

${ }^{13}$ K. Tanaka, A. Narazaki, and K. Hirao, Opt. Lett. 25, 251 (2000).

${ }^{14}$ V. Nazabal, E. Fargin, J. J. Videau, G. Le Flem, A. Le Calvez, S. Montant, E. Freysz, A. Ducasse, and M. Couzi, J. Solid State Chem. 133, 529 (1997).

${ }^{15}$ M. Guignard, V. Nazabal, F. Smektala, J.-L. Adam, O. Bohnke, C. Duverger, A. Moréac, H. Zeghlache, A. Kudlinski, G. Martinelli, and Y. Quiquempois, Adv. Funct. Mater. 17, 3284 (2007).

${ }^{16}$ A. Lepicard, F. Adamietz, V. Rodriguez, K. Richardson, and M. Dussauze, Opt. Mater. Express 8, 1613 (2018).

${ }^{17}$ M. Dussauze, E. Fargin, M. Lahaye, V. Rodriguez, and F. Adamietz, Opt. Express 13, 4064 (2005).

${ }^{18}$ M. Dussauze, E. Fargin, A. Malakho, V. Rodriguez, T. Buffeteau, and F. Adamietz, Opt. Mater. 28, 1417 (2006).

${ }^{19}$ M. Dussauze, V. Rodriguez, A. Lipovskii, M. Petrov, C. Smith, K. Richardson, T. Cardinal, E. Fargin, and E. I. Kamitsos, J. Phys. Chem. C 114, 12754 (2010).

${ }^{20}$ A. V. Redkov, V. G. Melehin, and A. A. Lipovskii, J. Phys. Chem. C 119, 17298 (2015)

${ }^{21}$ A. V. Redkov, V. G. Melehin, D. V. Raskhodchikov, I. V. Reshetov, D. K. Tagantsev, V. V. Zhurikhina, and A. A. Lipovskii, J. Non-Cryst. Solids 503-504, 279-283 (2018).

${ }^{22}$ L. Karam, F. Adamietz, D. Michau, C. Gonçalves, M. Kang, R. Sharma, G. S. Murugan, T. Cardinal, E. Fargin, V. Rodriguez, K. A. Richardson, and M. Dussauze, Adv. Opt. Mater. 8, 2000202 (2020).

${ }^{23}$ T. Cardinal, E. Fargin, G. Le Flem, and S. Leboiteux, J. Non-Cryst. Solids 222, 228 (1997).

${ }^{24}$ M. Dussauze, E. I. Kamitsos, E. Fargin, and V. Rodriguez, J. Phys. Chem. C 111, 14560 (2007).

${ }^{25}$ V. Rodriguez, D. Talaga, F. Adamietz, J. L. Bruneel, and M. Couzi, Chem. Phys. Lett. 431, 190 (2006).

${ }^{26}$ E. I. Kamitsos, A. P. Patsis, M. A. Karakassides, and G. D. Chryssikos, J. Non-Cryst. Solids 126, 52 (1990).

${ }^{27}$ J. E. Shelby, Introduction to Glass Science and Technology, 2nd ed. (Royal Society of Chemistry, Cambridge, 2005).

${ }^{28}$ V. Rodriguez and C. Sourisseau, J. Opt. Soc. Am. B 19, 2650 (2002).

${ }^{29}$ Z. X. Shen, X. B. Wang, M. H. Kuok and S. H. Tang, J. Raman Spectrosc. 29, 379-384 (1998).

${ }^{30}$ M. Dussauze, E. Fargin, V. Rodriguez, A. Malakho, and E. Kamitsos, J. Appl. Phys. 101, 083532 (2007).

${ }^{31}$ M. Dussauze, V. Rodriguez, F. Adamietz, G. Yang, F. Bondu, A. Lepicard, M. Chafer, T. Cardinal, and E. Fargin, Adv. Opt. Mater. 4, 929 (2016).

${ }^{32}$ G. Guimbretière, M. Dussauze, V. Rodriguez, and E. I. Kamitsos, Appl. Phys. Lett. 97, 171103 (2010).

${ }^{33}$ T. Suzuki, J. Anzai, Y. Takimoto, K. Uraji, K. Yamamoto, and J. Nishii, J. Non-Cryst. Solids 452, 125 (2016).

${ }^{34}$ P. G. Kazansky and P. S. J. Russel, Opt. Commun. 110, 611 (1994).

${ }^{35}$ R. Stegeman, C. Rivero, K. Richardson, G. Stegeman, P. Delfyett, Y. Guo, A. Pope, A. Schulte, T. Cardinal, P. Thomas, and J.-C. Champarnaud-Mesjard, Opt. Express 13, 1144-1149 (2005). 